Open Access

\title{
A call for promoting ownership, equity, and agency in faculty development via connected learning
}

\author{
Maha Bali ${ }^{* *}$ (D) and Autumm Caines ${ }^{2}$
}

\author{
* Correspondence: \\ bali@aucegypt.edu \\ ${ }^{1}$ American University in Cairo, \\ Virtually Connecting, Cairo, Egypt \\ Full list of author information is \\ available at the end of the article
}

\begin{abstract}
For transformation to occur in learning environments and for learners, higher education must first consider how such transformation will occur for the designers and facilitators of learning experiences: the university teachers or educators we call faculty (in the US), instructors, lecturers or professors or, in some instances, university staff. For the purpose of this article, we will refer to them as educators or faculty, and the process of their professional development as educational development or faculty development (more historically common in the US context). We aspire towards universities in the future that cultivate connected, participatory educational development that crosses institutional and national boundaries, and which takes equity, social justice and power differences into consideration, promoting educator agency. We propose theoretical underpinnings of our approach, while also highlighting some examples of recent practice that inspire this direction, but which are small in scale, and can provide springboards for future approaches that may be applied on a wider scale and become more fully integrated, supported and rewarded in institutions. Our theoretical underpinnings are influenced by theories of heutagogy and self-determined learning, transformative learning, connectivist and connected learning, and an interest in equity.

We share models of alternative approaches to educator development that take advantage of the latest advances in technology, such as \#DigPINS, Virtually Connecting, collaborative annotation, and dual-pathway MOOCs. We then share a semi-fictional authoethnography of our (the authors') daily connected lives, and we end by highlighting elements of the models we shared that we feel could be adapted by institutions to achieve educator professional development that is more transformative, participatory, and equitable.
\end{abstract}

Keywords: Faculty development, Transformative learning, Heutagogy, Connected learning, Connectivism, Higher education, Educational development, Equity

\section{Introduction: Why this direction/approach?}

"Imagination of how things could be otherwise is central to the initiation of the transformative process". (Mezirow, 2006/2018 p. 119).

In responding to a call to address the future of universities in an educational technology journal we thought carefully about our direction and approach. We wanted to be sure that we were approaching this question in a serious and non-predatory way, as forecasting the future is a ubiquitous activity in the field of educational technology, and one that we fear is too often taken on in irresponsible ways. There is no doubt that

(C) The Author(s). 2018 Open Access This article is distributed under the terms of the Creative Commons Attribution 4.0 International License (http://creativecommons.org/licenses/by/4.0/), which permits unrestricted use, distribution, and reproduction in any medium, provided you give appropriate credit to the original author(s) and the source, provide a link to the Creative Commons license, and indicate if changes were made. 
looking forward to envision what may come is important; to ignore the future would make us vulnerable to dangers that are easily seen, unaware of obvious opportunities, and would ultimately result in a failure of imagination. Still, the work of telling the future has a long history of coming from charlatans and con-men who care more about selling a product than making transformative change.

Audrey Watters (2016) makes it clear that this kind of unscrupulous future-telling is not confined to the snake oil salesmen of yesteryear who traveled about in a horse-drawn cart, but is ever present in the world of educational technology. In her public talk and essay entitled The Best Way to Predict the Future is to Issue a Press Release, she gives example after example of inaccurate and fantastic predictions in educational technology from corporations, analyst firms, and futurists. She shows how none of these predictions are built on evidence and how they are always in favor of an "increasingly technological future".

In this article we advocate for and give examples of educational development opportunities for educators that encourage heutagogy with outcomes that focus on ownership and agency which can potentially lead to transformative learning. These are often open educational practices that use technology but which are rich because of the social interaction and open attitudes underlying the practices rather than the particular technologies involved. We call for a future with more of these kind of experiences rather than predict or forecast such a landscape. The reason for a call rather than a forecast is an important one rooted in the very reasoning for such an approach to educational development. The point of this article, much like the point of the educational development that it advocates for, is not to convince you of some already determined consequence. Rather, our goal here is to inspire further exploration and inquiry into methods that question deterministic narratives and to relay the kind of future we aspire towards.

\section{History of faculty development, evidence base and future aspirations}

In the work of Beach, Sorcinelli, Austin, and Rivard (2016), faculty development (sometimes called academic development and/or educator/educational development) is centered on the professional development of academic teaching staff at universities. They point out that while faculty development often focuses on teaching it rarely centers around the whole person. In their work, they differentiate between different ages of faculty development, starting with the age of the scholar (where scholarship in one's own field was considered sufficient for good teaching), the age of the teacher (where learning to teach became recognized as important to develop), developer (where educators were seen to need support from faculty developers at their institution), the age of the learner (where centering student learning became more important than teaching), the age of the network (which focuses on the ways departments and entities within and outside institutions collaborate in order to enhance learning, in a way de-centering the instructor as solely responsible for learning in the classroom), and the age of evidence (which emphasizes the importance of gathering evidence of what works and what does not). These ages are of course not mutually exclusive.

There are several points to discuss here. First of all, let us draw attention to the shift from the age of the teacher to the age of the student where we see a change in nomenclature and focus from teaching to learning or to "teaching and learning". While faculty development rhetoric has evolved from being teacher-centric to learner-centric, faculty 
development itself is not necessarily centered around the learner (who in this case is the educator). Even when attempting to address learning needs via a needs assessment and gathering feedback to promote an evidence-based approach, experiences are often designed in modular, disconnected ways that remain authoritative (Webster-Wright, 2009, cited in Kalir, in press). So much of faculty development is one-size-fits-all and arranged according to preset schedules and locations - and by doing so, will consistently fail to meet the needs of those whose interests are marginal or different from the majority. Moreover, the understanding of "network" in the institutional sense fails to account for the individual level of the Personal Learning Network (PLN) where educators can build connections and relationships that advance their ongoing learning outside of institutional structures and boundaries - finding mentors and collaborators who have no hierarchical relationship with them internally. A university educator may, in the course of their career, need to call for help from various members of their own institution, but they should also have enough agency to find that support elsewhere if appropriate.

When offering workshops and evidence-based approaches, educational development centers make decisions on behalf of educators based on what has worked in the past for the majority. This often ignores the few who have more specific needs, and by following best practices taken from other contexts, may end up being less relevant to local contexts (Hill, 2009 cited in Kalir, in press). Occasionally there will be a direction towards a new trend that administrators find interesting or valuable regardless of evidence. Neither of these approaches are sufficient for two reasons: first, they often do not address needs of minorities or educators who are marginalized in particular ways and second, they are unlikely to meet specific needs of faculty e.g. In their disciplines or a specific area of interest few in one's institution share.

Another critique of traditional face-to-face faculty development is that even though educators may have choices as to which opportunities to take advantage of, they are still restricted by what is offered and available and what is rewarded by the institution as valid professional development. This is inevitably a limited array, often one-size-fits-all, and likely to be fixed in time and space. Time is an increasingly scarce resource in academia, and usually more efficiently used in conducting research which is more highly valued and rewarded in most higher education.

The inflexibility of time and space of traditional faculty development is inherently inequitable. It discriminates against educators who have family responsibilities (such as parenting or caring for an elderly relative) that limit time available to spend on campus; it discriminates against contingent faculty and graduate students who undergo clear opportunity costs when they spend their time on profession development-time they could have spent earning money elsewhere or finishing their degrees faster. Face-to-face conferences and workshops continue to reproduce inequality in access to those whose time and mobility are more limited. It discriminates against those who live far away from additional opportunities for professional development and cannot afford the cost of constantly traveling to learn what others can with less cost and effort.

How do we offer educational development to people with different teaching philosophies? What are the values behind using particular approaches or encouraging the use of technology in particular ways either by rewarding it monetarily or otherwise, or by normalizing certain practices such as Learning Management System (LMS) use or by 
partnering with corporate entities whose agendas will rarely, if ever, be centered towards the public good?

Our recommended approach is to consider what we can learn from heutagogy, connectivism and transformative learning and with an equity orientation, in order to facilitate learning experiences where educators map their own individual learning pathways by looking within and beyond the institution for learning opportunities and mentorship, and doing so with support from local environments. We suggest this can result in a more transformative, sustained and equitable educational development experience, which respects individuals and better addresses their needs and goals, while doing so in supportive communal spaces. Although our approach often relies on technology, the philosophical underpinnings are not dependent upon technology, but instead utilize it for a purpose. Technology here mainly serves the purpose of allowing flexibility of time and space, the latter of which allows for the development of continuous or sustained affinity spaces across wider geographical differences than would be typical in professional development opportunities. Even as we share specific examples to demonstrate our aspirations, we recognize that these models may not fit every educators' needs and preferences. We encourage readers to abstract the important elements of each innovative practice and consider how it might be adapted to their own context, with or without technology. And while many of these models exist, faculty development centers (and other support departments such as libraries and IT departments) at institutions are rarely the ones that initiate them (although in some of our examples, they do) and educators may not naturally find these opportunities on their own without the necessary support to see them as viable options.

\section{Philosophical underpinnings}

\section{Transformative learning}

Transformative learning is

"the process by which we transform problematic frames of reference (mindsets, habits of mind, meaning perspectives) - sets of assumption and expectation - to make them more inclusive, discriminating, open, reflective and emotionally able to change. Such frames are better because they are more likely to generate beliefs and opinions that will prove more true or justified to guide action" (Mezirow, 2006/2018 p. 116).

While transformative learning is touted in many approaches to undergraduate and even graduate education, when it comes to faculty development we often do not see a focus on it. Educator professional development, as anyone who works on teacher education or faculty development knows, often entails a process of unlearning assumptions built from years of being the recipient of ineffective pedagogy. Anyone who works on educating other educators is involved in the process of trying to make the educator question their assumptions, reflect on their practice, and embrace alternatives after critically evaluating their suitability in their context, in order to guide their action. As Freire (1970) and proponents of critical pedagogy contend, education is always political, and any action an educator takes in their classroom or teaching, has political implications and can influence social change. Therefore ignoring what we know about transformative learning in our educational development efforts is an oversight, because 
"transformation theory contends that adult education must be dedicated to effecting social change, to modifying oppressive practices, norms, institutions and socio-economic structures to allow everyone to participate more fully and freely in reflective discourse and to acquiring a critical disposition and reflective judgement" (Mezirow, 2006/2018, p. 120). If university educators are responsible for cultivating values of democracy and social action in students, they themselves should be learning in transformative ways that promote these capabilities and attitudes. Heutagogy, an adult learning theory, builds on transformative learning, and we discuss that in the next section.

Essential elements of transformative learning are critical self-reflection, including questioning one's own assumptions, and "participating fully and freely in dialectical discourse to validate a best reflective judgement" (Mezirow, 2006/2018, p.118). Transformation may occur either suddenly (what Mezirow terms "epochal") or progressively over time (what Mezirow calls "cumulative"). Since such transformation frequently occurs outside a person's conscious awareness, reflecting in community and dialogue helps learners develop a metacognitive awareness of connections between theory, values and practice. In our experience supporting other educators, we have seen how one-off faculty development efforts such as one-hour or one-day workshops might promote epochal learning, but a more sustained approach with a community of learners (such as the examples we shall describe) offers opportunities for cumulative transformative learning, as well as more opportunities for epochal transformation, since the learning itself is continuously accessible. This also relates to Wenger, Trayner, and de Laat's (2011) model of assessing value creation in networks and communities of practice, in that some value is immediate, in the moment, while other learning is potential and the participant will notice its value later; some learning is then applied in practice, and the value might be realized if the outcomes meet the intentions, and later value can be reframed. One can imagine how a one-off workshop could produce sudden learning that would later have potential for application, but a more sustained reflective community supports opportunities for epochal learning, and reflection upon one's practice to recall what was previously learned and as one applies something new and assesses its success or failure.

\section{Heutagogy}

Heutagogy is an approach to teaching adults where learners are granted a high degree of autonomy, their learning is self-determined and "emphasis is placed on development of learner capacity and capability with the goal of producing learners who are well-prepared for the complexities of today's workplace." (Blaschke, 2012, np).

Heutagogy builds on the principles of transformative learning, and contends that the properties of social media enable heutagogy since they allow learners to consume and produce without reference to authority. The main difference between heutagogy and andragogy (a theory of adult learning) is that learners have full ownership of their own learning pathway with guidance from a facilitator - the learner designs and leads their learning process, including what and how to learn, not the facilitator (Hase \& Kenyon, 2000; Eberle, 2009 - cited in Blaschke, 2012). Acquiring competency and capability to adapt and apply learning in novel situations is an important focus of heutagogy (Blaschke, 2012). 
Essential components of heutagogy are self-reflection and "double-loop learning" (Blaschke, 2012), where double-loop learning involves two levels of learning. The first loop involves reflection on the problem-solving process from problem to action to outcomes, whereas the double-loop occurs when the learner additionally questions their own beliefs and assumptions and how they impact their thinking and action. This clearly connects with the metacognitive and self-reflective processes of transformative learning. Since heutagogy suggests social media supports these learning processes, we next discuss connectivism and connected learning, which arose for the same reason.

\section{Connectivism and connected learning}

Connected Learning (Ito et al., 2013) creates a framework for learning with modern technologies, focusing on equal opportunities for participation through social connections and engagement based on personal interests (Connected Learning Alliance, undated). Connectivism, a model for describing the way online networks influence the way people learn online, is a "pedagogical model that views knowledge as a networked state and learning as the process of generating those networks and adding and pruning connections." (Siemens, 2013, p. 8).

Connectivism focuses on how people acquire knowledge in complex, uncertain environments, via personal connections that build individual networks. The eight principles of Connectivism as laid out by Siemens (2004, n.p.) are:

- Learning and knowledge rest in diversity of opinions.

- Learning is a process of connecting specialized nodes or information sources.

- Learning may reside in non-human appliances.

- The capacity to know more is more critical than what is currently known.

- Nurturing and maintaining connections is needed to facilitate continual learning.

- The ability to see connections between fields, ideas, and concepts is a core skill.

- Currency (accurate, up-to-date knowledge) is the intent of all Connectivist learning activities.

- Decision-making is itself a learning process. Choosing what to learn and the meaning of incoming information is seen through the lens of a shifting reality. While there is a right answer now, it may be wrong tomorrow due to alterations in the information climate affecting the decision.

According to Downes (2014, n.p.), Connectivism sees a learner as "a self-managed and autonomous seeker of opportunities to create, interact and have new experiences". Rather than designing learning around particular knowledge and skills, connectivism would suggest we instead focus on "creat[ing] the conditions in which a person can become an accomplished and motivated learner in their own right" (Downes, 2014, n.p.).

Kalir (in press) contend that participatory networked digital and hybrid practices, while not unproblematic, have afforded educators professional development that has fed their curiosity and been more relevant to their daily practice, compared to previously pre-designed, rigid pathways in professional development. 
Equity

We would also like to highlight our interest in addressing equity in educational development. Here, we are interested in Gorski and Pothini's (2013) equity literacy model, which contends that we need to learn to recognize inequity, respond to it, redress it, and create and sustain equitable learning environments. Most of the models we share next have recognized and responded to inequity in one form or another.

One cannot speak about ownership and agency without recognizing that participants in any learning environment each have a different sense of self-efficacy, confidence, belief in their own agency, and willingness to take ownership, whether this is based on personality, past experience of marginality or power, or intersectional identity.

Kalir (in press) identified four elements of the design of an equity-oriented open educational practice as

1. Taking advantage of the open aspects of the web thus facilitating equity in participation, while recognizing that power imbalances will remain, but also technically using open source technologies that do not carry a corporate agenda and offer transparency

2. Using partnership with various stakeholders, thus creating space for multiple voices to influence the process, since "if we seek to generate equitable outcomes, the processes by which we enact change must be orchestrated such that equity is embedded in every stage" (Teeter et al., 2016, p. 52, cited in Kalir, in press).

3. Using openly accessible content, thus ensuring equity in access to material. However, we need to remember that equity in access does not necessarily lead to equitable outcomes (Czerniewicz, 2015).

4. Focusing on professional learning, thus attempting to be relevant to participants' interests and needs.

The particular project Kalir applied these principles to, Marginal Syllabus, will be described later in this article. However, the majority of the models we refer to use the open web (though not necessarily open source software) and open material for professional learning, embracing individual agency in a participatory environment.

The latter point about relevance to professional learning is particularly important in educator professional development. As demands on educators' time are many, requiring them to spend time on learning that seems less relevant to their immediate interests or needs, which holds no flexibility to fit within their other priorities, or goes unrewarded by administrators would likely create (justified) resistance from their side and be an unfair use of their labor.

\section{Choice of models}

"We are, when we are at our best, meant to unsettle assumptions, to reorganize our ideas of agency, and to push the boundaries of what is possible in a connected learning environment." (Morris, Rorabough, \& Stommel, 2013).

In the sections that follow, we present multiple models of professional development of educators that we feel partially address our aspirational values. While there are other 
models, we attempted to present a spectrum of possibilities within connected and connectivist approaches here, ones that, to different extents, promote some degree of heutagogy and transformative learning, and ones that address equity to varying degrees and from different lenses. Models we share include some that are institutional versus ones that are mostly extra-institutional; models that are fully online versus ones that are hybrid, and models showing a range of learner agency, time flexibility, and equity emphasis. None of these models alone achieves all we aspire towards, but offers a starting point to imagining what a future of educator development could be.

The models we share offer alternatives to the status quo, recognizing that

"even when knowledge may appear to be the solution, it can be partial and disempowering to all but the dominant groups. [There is a] need to contest such knowledge claims and to learn to transgress, rather than to conform... transformative spaces need to be found and... these should be about the creation of new opportunities, ways of knowing and ways of being". (Jackson, 2018, p. i, emphasis ours).

We recognize that some commonly existing practices achieve some of our aspirations. Faculty Learning Communities (FLCs, see Cox, 2004) build community and often involve critical dialogue, but are not guaranteed to be flexible enough for institution faculty members' time or interest or needs. Cox (2004) recognizes this, saying that about one third of faculty at his institution do not participate, whether out of disinterest or lack of time/priority. Some institutions such as University of Cape Town's Center for Innovation in Learning and Teaching, offer online courses, which afford flexibility of time and space but usually have pre-set content, or self-paced online modules which again afford flexibility but would not include critical dialogue. We feel the models we are sharing, while not exhaustive of all innovative approaches to educator professional development that afford agency, equity and transformative potential in a participatory environment, are diverse examples of what we are striving towards. We are able to offer more detail on DigPINS and Virtually Connecting because of our own involvement in them.

\section{\#DigPINS}

\#DigPINS is a fully online and networked educational development experience. The hashtag and acronym refers to the content of the course which covers Digital Pedagogy, Identity, Networks, and Scholarship as major topics. However, the content of the experience is not what is highlighted. Rather, the experience is focused on participants negotiating multiple online contexts through various online tools that span open and more private spaces to create a networked learning experience and an ongoing institutionally based online community. Cronin (2014), states that

"Open online spaces offer multiple opportunities for networked learning. Learners can establish new connections, within and beyond the classroom, based on their interests as well as the curriculum, and connect, share and work with others across the boundaries of institution, education sector, geography, time zone, culture and power level."

But how are faculty ever to create networked learning experiences in open online spaces for students if they have never experienced learning for themselves in these spaces? 
\#DigPINS attempts to create a transformational and heutagogical learning opportunities for faculty and (at some institutions) staff through modeling Connectivist and Connected Learning practices.

Each of the major topics are covered over a specific time period, most often one week each, through online content with a greater focus on conversation and online community building. The experience is intended to be delivered with a cohort of participants who are all affiliated with an institution. These participants work in open environments that can be viewed by the public but also in a backchannel where they are only in communication with one another. Other cohorts from other institutions may be working through \#DigPINS at the same time and there is, at times, opportunity for inter-institutional collaboration in the open environments.

The experience was originally conceived of, designed, and delivered in 2016 by Sundi Richard and Daniel Lynds at St. Norbert College (SNC), USA. as a project affiliated with the college's Full Spectrum Learning strategic initiative. Since its inception, a template of the \#DigPINS curriculum has been released under Creative Commons license and it has also been run at Davidson College, USA by Richard and at Kenyon College, USA by Joe Murphy. Additionally, Caines (co-author of this article) has continued to run the \#DigPINS experience at SNC since 2017.

A focus on ownership and agency is inherent in \#DigPINS as a foundational aspect of the course is digital identity and digital networks. Identity work lends itself directly to the highly autonomous and self-directed nature of heutagogy. Whereas instruction and other top-down pedagogies can provide content that discusses identity it is only through critical self-reflection and self-expression that one's identity is given room to grow. Participants are asked to analyze their current digital identity and relate differences between how they present themselves online as a professional, faculty member, scholar, and teacher as well as more personal aspects of their digital identity such as a mother, father, friend, etc. and how different tools enable or hinder this expression. Through the circulation and communication of this analysis, in dialogue with others who are similarly evaluating themselves, participants are given a space to learn about themselves and one another.

As the experience progresses, facilitator(s) distribute content and continue to engage participants in an ongoing conversation around the major topics through a heutagogical approach that promotes agency in those participating. Content is provided as a way to give structure and fuel conversation but by putting the emphasis on open dialog the facilitator(s) enable a space for participants to engage in self-directed learning. The template of the curriculum at digpins.org describes the facilitator's role as follows:

"Facilitators of \#DigPINS act as guides more so than instructors. They are not there to dictate right or wrong answers but rather to encourage each participant to consider their own digital identity, how they network through digital spaces to connect for positive change, and how that can impact their pedagogy and scholarship." (DigPINS Course Structure, 2018)

While there are structured readings and activities every week, much of the experience takes place as an ongoing conversation toward the making of meaning between the participants, between the participants and the facilitator(s), and between the entire 
community and the public. Public interactions are promoted by the facilitator often with the facilitator engaging their own network to converse in community with the cohort. Additionally, as time has progressed past participants of \#DigPINS have remained in the open spaces as well as in shared backchannel spaces and, at times, contribute to the community dialog.

\#DigPINS does not prescribe any particular digital technologies for delivering the experience; as part of the design process facilitators need to decide which digital technologies will be used. The tools chosen, together, need to enable channels of communication ranging from one to one, one to many within the cohort, and one to many in public. The experience calls for participants to critically examine expression and dialog in a range of public/private environments, and the participatory decision-making promotes agency and ownership. The design of the experience calls for this critical consideration to be part of the readings and content but it is enabled and enacted through the ongoing conversation which is shaped by the boundaries allowed in the technology. Participants reflect on how they choose what gets said in the public and what stays in-group in the backchannel. Grappling with this distinction, making decisions based on it, and figuring out how to use the technology to enact that decision enables faculty and professionals to not just become more fluent in their digital skills but to become more critical in their use of technology considering multiple contexts and power dynamics.

Many of the models that will be discussed in this paper are dependent on intrinsic motivation from individuals to be successful but we know that not everyone is inspired by purely intrinsic motivators. Furthermore, we recognize that even among faculty a commitment to personal lifelong learning in practice is not always valued or even practical. Because \#DigPINS is an institutional model there is much to be learned about the details of how it is implemented.

All of the institutions that have run \#DigPINS have implemented some kind of stipend program for at least some participants. Initial stipends at SNC were limited to faculty but in later years were opened, in part, to staff. The most recent iteration of institutional support of \#DigPINS at SNC is its alignment with a two part stipend program called the Full Spectrum Learning Stipend. The stipend is divided into two parts: Level One - which focuses on exploration and Level Two - which focuses on implementation. Level Two is dependent on Level One but is not a requirement of the award as a whole. This simply means that someone has to complete Level One before they can apply for Level Two but that applying for Level Two is an option not a requirement. It is also important to note that both levels are awarded at equal amounts.

The Level One exploration level is awarded simply by active participation in the \#DigPINS experience which is defined as:

"Active participation includes online discussion in text chat, blogging, twitter chat, video calls and other digital means around common readings, videos, and other content. \#DigPINS is designed to create a safe-to-fail (rather than fail-safe) environment in which participants can explore human-centered approaches to working with technology to create community and learning experiences." (Full Spectrum Learning Stipend, 2018) 
Level One of the stipend was opened to staff in 2018 with the intention that the larger outcome of the experience was to lay a foundation for a broader institutionally based online community with more voices from various levels of experience. For the weeks that discuss pedagogy and scholarship staff are asked to consider how they teach, perhaps in informal ways, in their work and for scholarship how they contribute to and influence their larger fields. For staff, 'pedagogy' often is not classroom teaching but informal teaching with students or even co-workers. Scholarship, for staff, could be presenting at a professional conference, hosting a webinar with a professional organization, or even starting a professional blog.

Level Two of the stipend focuses on implementation and is only available to those who teach and were first awarded a Level One stipend. The implementation stage is project based and has requirements of planning, enacting, and disseminating a reflection - "in their pedagogy or scholarship that includes an aspect of digital pedagogy, open education, hybrid and online learning, developing digital literacies/competencies/ citizenship in students, and/or other creative approaches to teaching and learning." (Full Spectrum Learning Stipend, 2018). By making the project based implementation stage dependent on an explorative, networked, and connected experience, a foundation is laid for transformative and heutagogical learning through self-reflection and dialog. \#DigPINS is still very young as a model but it is hoped that networked communities within and between institutions can be born from this initiative.

\section{Virtually Connecting}

Virtually Connecting (sometimes shortened to VConnecting or VC) "is a living enactment of connectivist/connected learning theory applied to hybrid conferencing in community." (Bali, Caines, DeWaard and Hogue, p. 227). VC's about page explains:

"The purpose of Virtually Connecting is to enliven virtual participation in academic conferences, widening access to a fuller conference experience for those who cannot be physically present at conferences. We are a community of volunteers and it is always free to participate." (Virtually Connecting, n. d.).

It is a "grassroots" volunteer movement which, in its finished product, uses web-based video conferencing to allow spontaneous hallway-type conversations between speakers and participants at a conference and those who cannot attend but would like to chat with those who do. A pair of onsite buddy/volunteer and a virtual buddy/volunteer (and often a larger team of volunteers) plan and implement this meeting with conference participants and put an open call to invite virtual participants to join the video conversations.

This becomes important for all constituents bringing an outside perspective to the conference participants, giving those who do not have the means to travel a glimpse of the conference, and providing the conference organizers with a boost to online attention and participation with the conference. Vconnecting was co-founded by an Egyptian (Bali, co-author of this article) and a Canadian living in the US (Rebecca J. Hogue) who were joined in co-directing VConnecting by 3 others from US (Caines, co-author of this article), Canada (Helen DeWaard) and Germany (Christian Friedrich). 
Equity is central to the concept of Virtually Connecting as it was initiated in order to provide access to networking and opportunities of social capital to educators who could not attend conferences. These are people who are often marginalized by this lack of access due to financial, social, logistical, health or other reasons including: academics who are geographically far from most edtech conferences in North America and Western Europe, contingent academics and graduate students who lack funding for travel, parents of young children, people with health issues that prevent travel, or people who cannot travel because of visa issues or travel bans. VConnecting breaks down hierarchies by bringing established conference speakers in conversation with early career individuals (virtually or in person) who may not normally have a chance to speak to them, even if they had attended the conference in person - as Rebecca Hogue has said, VConnecting boosts the social capital of both the onsite buddy/volunteer and the virtual buddies/volunteers and participants (in Bali \& Hogue, 2015). Moreover, VConnecting sometimes intentionally brings in lesser known guests from marginalized groups in order to highlight their work.

In a previous paper (Bali, Caines, DeWaard, \& Hogue, 2016), we explored how the informal conversations in $\mathrm{VC}$ mapped to connected and connectivist learning, and we reported survey results showing that, for the most part, $\mathrm{VC}$ met its values (written in the manifesto, Virtually Connecting n.d.) of improving the virtual conference experience by providing access to spontaneous conference conversations, and aiming towards inclusion.

The educational development that happens in Virtually Connecting is varied and layered depending on the level of involvement which will vary from individual to individual (Beckingham, 2018). For this article we will focus on the level of involvement of two groups: the group of volunteers versus the guests and participants. The main difference being that the volunteers spend more time coordinating and organizing prior to the streamed session while the guests and participants are only active in the moment of their streamed session. There are therefore two layers of dialogue.

The group of volunteer buddies are made up of educators, academics, and other interested parties from around the globe who are interested in advancing conversations around educational technology, instructional design, and open education across boundaries and especially towards creating greater equity around conferences. VConnecting events are planned beforehand by the volunteers in the community. Being part of the volunteer group is an educational development opportunity that builds digital literacies and online collaboration skills. Additionally, besides planning, logistics, and digital support volunteers also participate in the conversations which provide a space for critical self-reflection around the conference experience.

Guests and virtual participants are most often only active during the streamed session for this critical self-reflection. Onsite guests who are presenting or attending the conference are invited to come and reflect about their experience at the conference or relate some of what they are presenting about. Critical self-reflection is an essential part of transformative learning and often those who are attending conferences in person or from afar do not take the time to so. By providing a space for critical reflection on the experience of the conference Virtually Connecting provides an opportunity for transformative learning in the moment.

An unintentional but welcome dimension of VConnecting is that the actual conversations that occur are often critical due to the general disposition the community takes. Therefore, 
VConnecting offers participants opportunities to critique corporatization in some conferences, certain technopositivist directions seen as harmful by participants, and also to constantly be aware of who is not present at conferences and to get their point of view:

"the possibility to include their [virtual participants'] views on conference themes and trends is an enrichment of the overall conference experience...VC is pushing boundaries... VC made the invisible online lurkers of a conference like this a bit more visible to the organizers." (Friederich, 2016).

Shy participants found that eventually joining a conversation was enriching:

"I felt a bit shy and uneasy about being present "out in the open." But I joined the hangout, asked my questions to Dr. C... and it was great. I just can't describe the experience here. My experience in Turkish schools taught me to follow hierarchy and build it, even if doesn't impose any structures on me. But here I was talking to somebody influential in the field, asking some basic questions and getting answers." (Koseoglu, 2015, a graduate student at the time).

Another graduate student, Lisa Hammershaimb, wrote:

"As someone with very limited income, being part of Virtually Connecting has given me access to events that I otherwise would have no chance to attend. With this access comes pretty amazing content but even more comes invaluable exposure to the "human creator" that is behind behind every idea...One of my favorite parts of Virtually Connecting is its casual immediacy and spontaneous insight. Seeing the kind of "unplugged" version of people I've previously only encountered in highly polished + edited perfection is so refreshing". (Hammershaimb, 2016)

Participation in VConnecting involves a high degree of agency. Onsite and virtual buddies volunteer to work on a conference out of personal interest and are supported by other volunteers to do so. Participation virtually is also a choice: people are welcome to sign up and join the conversation, or to watch live, or to watch a recording. People who watch live may leave questions on Twitter which speakers may be able to respond to. Since every participant in vconnecting does so by choice, choosing which conference and time and conversation to participate in, and whether to join the video or watch the livestream or recording online, it is a good example of self-determination in that the learner decides their own path: which learning to prioritize, which format to do it in, and when to do it. The facilitators only offer dates and times and opportunity to access a conversation many people would never have had the chance to have.

Virtually Connecting is also built on recognizing the power of conversation not presentations in adult learning. Most conferences give more time for presentations and little room for conversations. Moreover, it is difficult to have spontaneous hallway conversations without knowing someone beforehand. Virtually Connecting creates a hospitable space to hold such conversations and facilitates them for people who wouldn't normally have access. It also creates space for reflection at conferences which usually does not happen while everyone is busy experiencing the actual conference. As 
Berman (2015) wrote, it "virtualizes the right part of the conference...the personal interaction".

Critiques of Virtually Connecting mentioned in Bali et al. (2016) and presented in Bali et al. (2017) include the fact that the supposedly open and hospitable community may appear cliquish to those outside the community, that it may reproduce some of the power dynamic of conferences by re-centering those already in power(e.g. keynote speakers), and that it may meet some people's needs but be intimidating or uncomfortable for people who are shy or do not like appearing on video, or even do not really have access to technical infrastructure or digital literacy thresholds required to participate. Even though VConnecting uses freely available technology (Google hangouts on Air that livestreams and records to YouTube), some countries ban Google and/or YouTube, and some individuals prefer not to deal with Google. Overall, however, VConnecting is considered a form of open educational practice that provides a partial solution to the problem of limited access to social capital at conferences. While it has no direct institutional reward, occasionally conferences will offer complimentary registration to one or more Vconnecting volunteers, and the connections made during these events enhance the professional standing of participants. Additionally, participants may be able to make their learning via Vconnecting visible by highlighting the connections in their tenure/renewal portfolios and how they influenced them. For institutions that reward service, volunteering for Vconnecting would be considered as service to the profession and also a form of scholarship similar to moderating a panel at an in-person event.

\section{Collaborative reading: Twitter Journal Club and open web annotation with Marginal Syllabus}

Both Twitter Journal Club and Marginal Syllabus offer non-traditional approaches to online collaborative reading of texts, each of them addressing equity from different angles. Both of them naturally gain traction from a synchronous event which can continue asynchronously. By focusing on conversations around texts, rather than the texts themselves, they promote transformative learning as dialogue over affirming and clarifying participants' thoughts and experiences, rather than submitting to traditional authority of the text. Both approaches also do not require "pre-reading": participants are welcome to start reading the text for the first time during the event.

\section{\#TJC15}

Twitter Journal Club (TJC15), founded by Laura Gogia is "an open, unstructured, academic reading group found on Twitter, [and] provides meaningful learning experiences while embracing the holistic and messy nature of learning" (Gogia \& Warren, 2015, n.p.). It challenges traditional face-to-face reading groups in that participants meet synchronously to start reading an article live (with no expectations of pre-reading, no shame in not having read) and each person is free to live-tweet aspects of the article that resonates with them or connect it to their own life experiences, and to reflect with others (including sometimes the author). These conversations start synchronously but often continue asynchronously beyond their starting point.

Gogia and Warren mention how TJC15 offers: 
"opportunities to care, in terms of emotional and intellectual engrossment, relational and personal interest, and kindness and mutual respect. As such, we find this alternative, digital approach to academic reading one that engages its participants in uniquely creative, playful, and human ways of learning even as it augments and challenges traditional academic practice" (Gogia \& Warren, 2015, n.p.).

Gogia (Gogia \& Warren, 2015, n.p.) writes about how her previous experiences of faculty reading clubs had "no place for the connection of ideas to emotion or life experience" and was missing the "relational, human dimensions to Nodding's care that motivates me to learn more". The "culture of permissiveness" in TJC15 encourages reflection and agency of participants who previously may have felt excluded from expert-focused academic conversations, and TJC15 conversations were often enriched by participation from the article authors (Gogia \& Warren, 2015).

\section{Marginal Syllabus}

Marginal Syllabus is a faculty development project which uses Hypothes.is to collectively annotate socio-political texts. Those who lead the project believe that open web annotation promotes educator agency and has the ability to foster equity-centric dialogue. This approach is inspired by the transformative potential of openness in education, while recognizing that the use of technology for connection still carries implications for politics and equity (Kalir \& Perez, 2019). Texts which tackle equity issues are chosen (sometimes by the leaders, sometimes crowdsourced) and scheduled for annotation and promoted openly on Twitter. In the past, these "annotatathons" were done over a short period of time (usually an hour) but were later expanded to multiple days in order to facilitate inclusion of more participants from different timezones and with less flexible schedules (Kalir, in press).

Collaborative digital annotation of readings allows geographically dispersed individuals to share the act of reading, and facilitates their reflection together, using tools such as Hypothes.is https://hypothes.is which allows sentence-level commenting on any internet-based text using multimedia annotations (Zamora \& Bali, in press).

As mentioned earlier (Kalir, in press) this project was designed with equity in mind. The use open source software for social and technical accessibility, the involvement of multiple stakeholders in decision-making (working flexibly within conflict), the use of open content and the emphasis on relevance to professionals' practice and context. The approach reframes annotation of texts as conversation, thus fostering critical dialogue among participants which can support transformative learning.

It is difficult to find any glaring limitations with either the approach of \#TJC15 or Marginal Syllabus. While both these approaches offer learning benefits, it would also be expected that some learners prefer to read alone and not be distracted by other people's comments on an article. It is also possible that a participant may wish to read something different. However, participants always have these choices.

\section{cMOOCs and dual pathway MOOCs}

The philosophical constructs of Connected Learning and Connectivism that we highlighted above can be seen in practice in Connectivist MOOCs or cMOOCs. Connectivist Massive Open Online Courses (cMOOCs) are open online learning 
experiences that are different from xMOOCs. xMOOCs are often offered by institutions on known platforms such as Coursera, EdX and FutureLearn, and are usually structured in particular ways set by instructors or course designers. Whereas cMOOCs are more loosely structured, with a framework provided by course instructors, and a large proportion of learning occurring distributed across participants' social media presence on spaces like blogs, Twitter and Facebook, who connect and collaborate to extend knowledge in the course (Bali, Crawford, Jessen, Signorelli, \& Zamora, 2015). cMOOCs are "based on connection rather than content, which looks more like an online community than a course, and doesn't have a defined curriculum or formal assignments" (Downes, 2015). Crosslin (2018, p.132) emphasizes how in cMOOCs,"control of power has shifted from a centralised instructor to a network of connections, and where content acquisition has shifted from a centralised expert to a nebulous connection of shifting elements and participants".

There are MOOCs that neither fit the $\mathrm{xMOOC}$ nor the $\mathrm{CMOOC}$ end of the spectrum but still fit into the example of Connectivism and Connected Learning that we are identifying here. One example is such as Ross, Sinclair, Knox, Bayne, and Macleod's (2014) eLearning and Digital Cultures MOOC (\#edcmooc), which was offered on Coursera via the University of Edinburgh, but which gave learners lots of choice over which material to engage with, and whether to engage on social media or Coursera discussion forum, and which did away with quizzes entirely and instead had assessment via final artifact which learners had agency to choose (see Ross et al., 2014). Dual pathway MOOCs, which have been run several times and will be described below, offer both a structured and an unstructured pathway, and encourage participants to switch pathways as they see convenient at any point during a MOOC.

Connectivism and Connected Learning also of course occur outside of a MOOC framework, in digital networks. Relationships and connections between participants of a social network occur, potentially forming Personal Learning Networks (PLNs), communities of practice or affinity spaces. A community of practice, online or offline, "entails a shared domain as a source of identification" among community members (Zamora \& Bali, in press), and is differentiated from affinity spaces which are "geographically distributed, technologically mediated, and fluidly populated social groupings" Gee \& Hayes (2012, p. 135) and being based on interests which may not be professional in nature. (Gee \& Hayes, 2012, p. 137) assert that "human learning becomes deep, and often life changing, when it is connected to a nurturing affinity space".

On the other hand, the PLN (Personal Learning Network) is "a vibrant, ever-evolving and flexible group of connections" (Zamora \& Bali, in press) that each individual develops, which may or may not intersect with communities of practice or affinity spaces the person belongs to. As such, the PLN offers the most agency and heutagogy within any model for learning, because it is centered on each individual building and leveraging their own connections. However, such networking and connections are not equally accessible to all who try to form them, and as such, more structured and organized learning experiences can help someone begin to build a PLN.

The majority of participants in any type of MOOC is often adults, participating for their personal reasons such as their ongoing professional development, and only a few are seeking formal certification (Hew \& Cheung, 2014, cited in Crosslin, 2018). The 
idea and practice of a dual pathway (sometimes called dual-layer) MOOC is one that is built on heutagogy and an interest in equity. Participants are offered two parallel pathways to the MOOC, one structured by following an instructor-designed path, and one more connectivist, following the learner's desired path and involving connection with other participants. Each participant is encouraged to switch between these paths throughout the MOOC as they see fit. This is a heutagogical model that gives ownership and agency to the learner and respects their preferred approach to learning. It is equitable because it does not assume that each learner is independent and digitally literate enough to cover each topic in a connectivist manner, so the support of the instructor-centric structured model is available when needed, and at the same time, the opportunity to learn differently is offered to those who prefer it.

In practice, while many learners find the choice in the learning experience of a dual pathway MOOC positive, there are sometimes barriers caused by technical limitations, such as learners' inability to consistently see what is happening in the pathway they are not currently following (Crosslin, 2018). The first MOOCs run using this dual pathway approach was the edX Data, Analytics and Learning course (DALMOOC), run by the University of Texas at Arlington.

\section{Untethered faculty development (Jill Leafstedt and Michelle Pacansky-Brock)}

"Faculty development is in dire need of transformation to reflect the realities of teaching in digital, online environments." (Leafstedt \& Pacansky-Brock, 2016a).

The model proposed by Leafstedt and Pacansky-Brock (2016a, 2016b) reflects the importance of faculty learning in online and blended formats, while developing digital literacy and respecting faculty's needs for "multiple points of access and multiple modes of interaction", including asynchronously accessible online resources, synchronously joining face-to-face sessions via video conference, watching recorded sessions, and facilitating dialogue among and with faculty before, during and after professional development experiences (Leafstedt \& Pacansky-Brock, 2016a). This offers equity such that faculty whose time is more limited or who are geographically more distant from campus are able to participate in professional development activities more easily.

Importantly, this approach provides ongoing rather than one-off support. This model was implemented at California State University, Channel Islands, which has several geographically dispersed campuses, and as such, attempts to equitably address the needs of faculty across these campuses. This approach is explicitly built on principles of open and connected learning, and intended to influence the daily practices of faculty, and aims to overcome barriers of time and space while promoting lifelong learning in community (Leafstedt \& Pacansky-Brock, 2016b).

\section{A week in the life of Caines and Bali: semi-fictional autoethnography}

The kind of participatory connected learning experiences that we are advocating for are not easily described. Because they occur in complex networked environments with many overlapping connections, trying to relate them in a linear format such as text becomes quite difficult. We have provided the models above to act as case studies and individual examples. However, to give a more personal outlook of what it means to teach 
and learn in participatory connected learning environments we are also including this semi-fictional autoethnography of a typical week in lives of the authors, Bali and Caines. We are both co-directors of Virtually Connecting. Bali is based at the American University in Cairo in Egypt and Caines is based in St. Norbert College in the USA. We both work in the area of educator professional development.

$\sim \sim$

Bali is heading for bed at $10 \mathrm{pm}$, Cairo time, and checks her Twitter feed. She finds there is a new article being collaboratively annotated starting today, via the \#marginalsyllabus hashtag. She checks out what it's about and starts posting some annotations on her phone and responding to annotations of others, until she's too tired to continue. She plans to continue tomorrow, but posts a tweet about the annotation activity for others in her PLN who might be interested, tagging a few who would be particularly interested. It is an article she would not have normally read in her day to day work, but it inspires her to refer to some of its ideas in her class next week.

Caines is one of the people Bali tags on the tweet; it is $3 \mathrm{pm}$ Green Bay time and she is almost at the end of her work day. She checks out the article and realizes the topic fits the \#DigPINS discussions she has been facilitating with a cohort of instructors at her institution. Though the article is not part of the prepared content for the week, Caines shares the article and the \#marginalsyllabus annotation event with the \#DigPINS group by tweeting the article using \#DigPINS and \#marginalsyllabus and by posting the article and a description of the event in the \#DigPINS backchannel on Slack. The participants are already familiar with the annotation tool from an earlier structured activity in \#DigPINS and some of them jump into the \#marginalsyllabus annotation with some thoughts on the article. Additionally, someone participating in the \#marginalsyllabus annotation saw the cross-listed tweet and started inquiring with Caines about what exactly \#DigPINS is all about and Caines pointed them to the openly licensed curriculum.

The next morning, Bali wakes up to some Slack notifications from the Virtually Connecting Buddies team. They will add one more guest to the session at a German conference this week. The session takes place in the afternoon German time, and includes virtual participants from the US (Caines), France, UK, Egypt (Bali) and Australia. In Slack, Caines and some of the other buddies are communicating about updating the blog post and promoting the event on Twitter as well as other technical details surrounding the event. On the way to work, Bali is listening to an audiobook of Parker Palmer's, 1998 book and hears this part which resonates with her deeply: "our willingness to try, and fail, as individuals is severely limited when we are not supported by a community that encourages such risks" (p. 144), and she tweets it out tagging several people in her PLN who have particularly inspired and encouraged her to take risks, including Caines.

The day of the Virtually Connecting session everyone logs in a few minutes before the time to go live, across their various time zones - it is afternoon at the conference location in Germany and for Bali but it is early morning for Caines and evening for the Australian participant. As the participants join the call they are in connection with one another but the live stream has not yet been started so no one from the outside can see them. Since they are not live streaming yet, the tone is much more informal and lighthearted. Bali has taken on the role of the lead Virtual Buddy for this session and so she 
greets each participant as they enter noting the quality of their audio and video and troubleshooting with them if necessary. Once those who are onsite at the conference join the call with the onsite guests Bali similarly checks with them about the quality of their connection and once determining that all technology is working as well as can be expected everyone prepares to go live. Bali double checks to make sure that everyone is aware and consenting to the conversation being live streamed and recorded before she starts broadcasting the stream. Once she does, Caines and other virtual participants Tweet the link to the live stream on the conference hashtag and from time to time Tweet out insights from the conversation.

The guests are from Cameroon and the UK, and the onsite buddy who facilitates their connection from Germany is himself German, and the conversation starts with recaps of what has been happening at the conference but early on the guests begin to relate some critiques of the activities of conference organizers. Caines recounts a similar experience related to participant tracking at a US edtech conference. Everyone seems to agree that this problematic trend is increasing despite criticism from several in the field who have blogged and directly confronted conference organizers about these issues. Some of the virtual participants are Tweeting about these concerns while Caines and the guests are recounting these examples which stirs more conversation on Twitter and at the conference. After the session and conference are over the German onsite buddy blogs about this conversation and how VConnecting helps create space for such critical and dissenting conversations and for listening to perspectives of people not present at the conference.

The next day, Bali runs an open online Twitter activity with her students and invites her PLN to participate in this Twitter Scavenger Hunt about educational games. She tags people she knows in Egypt, US, UK, Ireland, Austria, Australia and South Africa who might be interested, and several of them respond to her students. Meanwhile, Caines is facilitating \#DigPINS and has ten faculty members who have analyzed their digital identity for a week. She has a video call scheduled with the participants to discuss their self-analysis and she will use many of the technical and hospitality skills that she uses in Virtually Connecting to work with them. This call will not be public or recorded to provide a space for the participants to discuss identity without the public eye. In the weeks that follow the \#DigPINS participants will be asked to communicate more publicly and Caines will reach out to her PLN and see who might be interested in engagement.

Besides taking on leadership roles where they are designing and facilitating these experiences, Bali and Caines use these heutagogical and transformational learning approaches in the weeks ahead in their own learning. Bali is giving a workshop locally about critical pedagogy soon. She has very few people in her face to face surroundings who understand critical pedagogy enough to give a workshop on it, so she blogs her thoughts and asks some people to give her feedback by posting the link on Twitter and adding hashtags to some recent MOOCs she had participated in, as well as posting it in the VConnecting buddies Slack \#random channel. Several people comment on ways of improving the activities and someone suggests a change of order. Most of the suggestions make sense. One does not apply to her context, so she ignores it. At the same time, Caines is excited that her institution is implementing a Domain of One's Own (DoOO) initiative. Besides having managed many of her own domains for several years 
and having helped to collaboratively maintain domains and sites for several of her projects, Caines is attracted to the philosophy behind DoOO with its focus on ownership and agency. Still, Caines knows that Domain of One's Own, especially as it is deployed institutionally, is a complex idea that often becomes problematic without critical dialog. Because the project is so new she is having trouble putting her ideas into a blog post, however, in the weeks ahead she calls on various members of her PLN to ask specific questions about technical deployment and larger philosophical concepts.

$\sim \sim$

In this brief semi-fictional autoethnography, we have highlighted how our connected learning days and our PLNs interweave to embolden each of us in taking risks within a supportive community, and broaden our access to learning resources and conversations when we need them. While we have institutional roles, we have agency such that much of our learning takes place outside of institutional boundaries, in times and online spaces that we seek and choose. Open practice supports connection because it enables people doing similar practices or who share similar values to find each other, at whatever stage of their learning. While it takes time to build a PLN and a supportive learning community such as VConnecting that one can trust for deep and critical conversations, they can become eventually become sustaining, and feed back into supporting us to do our institutional faculty development and teaching roles with more knowledge and confidence. It would be difficult, for example, to conduct a Twitter Scavenger Hunt online or facilitate \#DigPINS if the teacher/facilitator had not already built a PLN. It would be difficult to have hybrid conference conversations without building connections with participants ahead of time to enable these conversations (perhaps even more difficult than when you are in a conference onsite and know no one). Transformative learning is possible because these connected experiences afford us ongoing reflection in community, whereas living the day-to-day without stopping to reflect can hinder one's ability to take learning deeper and question the connections between our practices and our values (the VConnecting conversation we mention is a great example of this).

\section{Discussion}

We are strong believers that "the true benefit of the academy is the interaction, the access to the debate, to the negotiation of knowledge - not to the stale cataloging of content" (Siemens \& Cormier, 2010, n.p.) and that this should be the case in our educational development, in how we learn to teach and to reflect on our teaching, not just in our academic disciplines and research. However, we should continually question who has access to this debate, who feels they have the right to participate in negotiation of knowledge, and whose knowledge is being negotiated and discussed? Whom do we exclude?

Dialogue and reflection with others is central to transformative learning, learning that will create deep and lasting change in our practice because it is based on reflection on how our beliefs and values influence our practice, and the connections we make with others in the process, facilitated by modern technologies, require the development of digital literacy and investing time in order for connectivist learning to bear fruit and meet its potential:

"Working with and through each other should not be seen as a liability, a hassle. It is a process that can transform us. We remember Bakhtin here: "I am conscious of 
myself and become myself only while revealing myself for another, through another, and with the help of another... I cannot manage without another, I cannot become myself without another" (1981, p. 287).” (Bali \& Sharma, 2014, np).

It is also important to recognize the differences between working in private spaces such as Learning Management Systems or our own institutions, versus open, public spaces, which offer both risks and transformative potential (Cronin, 2014). Both afford us the opportunity to learn with others, but they are very different environments with different potential risks and benefits. Whom you learn with and from is wide open and global once you take it to the open web, and yet an educator might be more likely to find people who share their most specialized interests in a global community than at their own institution - hence the power of the PLN, the online affinity space, the online community of practice, or the connectivist MOOC experience. But similarly profound experiences can occur in a largely face-to-face situation, or in a private online space such as a Learning Management System that includes people from different institutions or countries.

Institutional professional development can benefit from elements of the different models we have discussed above. \#DigPINS is already an institutional model that follows a less traditional pathway that affords agency to participants. Virtually Connecting is a grassroots movement that is completely extra institutional and challenges academic gatekeeping (Bali, 2018). Dual pathway MOOCs and untethered faculty development show how learning experiences can be designed flexibly to respect different learners' preferences. Marginal Syllabus and TJC15 are extra institutional collaborative reading opportunities, yet Marginal Syllabus partners with institutions to better meet the needs of various educators from K-12 to higher education.

Most of these models combine elements of public, open interaction, but there is often a degree of private interaction that supports each.

While one cannot deny the need for institutions to provide locally contextualized professional development, that indeed, it is the institution's duty to do so, we suggest that institutions also consider incorporating more flexible opportunities that afford agency to educators to choose their learning pathways, participate in critical dialogue, and form networks beyond their immediate circle in order to promote future growth relevant to their individual needs.

It is important to differentiate between relying on individual educators' intrinsic motivation for their own professional learning, and individual educators becoming exploited through unrewarded affective labor. While we wish to encourage educators to seek their own learning path, we also recognize that if this goes unrewarded by the institution, this will discourage many from taking such a path. We point out that what institutions "count" as professional development must be flexible beyond traditional approaches that are familiar to them. Educators benefit from having the space to define their own learning goals and paths, and institutions will benefit in return when educators are given the freedom to develop in these ways. It is from these intrinsically motivated, heutagogical, and transformational faculty development experiences that educators will excel in their own teaching and scholarship. Institutions needing a more evidence-based approach could look along the lines of the Full Spectrum Learning Level Two stipend from St. Norbert College which requires that faculty show evidence that they have transformed something in their teaching or practice. While this might 
be more straightforward for institutions to reward it would be short-sighted overlook that level two of the Full Spectrum Learning stipend is dependent on Level One which requires the connected learning experience \#DigPINS and that both levels are rewarded equally. This model offers the possibility of rewarding learning separately from rewarding application. One may ask how to motivate faculty who are not intrinsically motivated to participate in professional development, but we feel that the majority of academics start out as lifelong learners, and given opportunities to choose their own learning path within reasonable time and space restrictions, will do so. The majority of current faculty development offerings at most institutions do not meet any of these criteria.

\section{Aspirations for educational development of the future}

Can we envision a new approach to educational development of university staff and faculty which embraces transformative learning and heutagogy? One that does the following

1. Recognizes and respects that different people have different professional development needs and that they have different priorities for how to go about achieving their goals?

2. Offers and rewards each person's chosen pathway towards their professional development, be it a structured approach provided by an institution, a self-determined path chosen by the individual, or somewhere in between?

3. Offers dialogic spaces for self-reflection in safe community, including for dissenting views?

4. Accounts for inequity in individuals' access and ability to benefit from existing, more traditional opportunities for professional development, and provide options that offer flexibility of time and/or space?

5. Involves educators in key decisions related to their professional development in their institution?

The challenge in designing learning experiences that afford the optimal amount of power and agency to learners (in this case, educators), is that it requires a "paradigm shift" for faculty development practitioners who are used to designing single pathway learning experiences that align objectives and content to particular, pre-set outcomes, to find ways to respect multiple learner epistemologies as valid within one learning experience (Crosslin, 2018, p. 141).

We have attempted here to offer multiple models that can inspire others in their endeavors to develop new approaches relevant to their context and to perhaps involve educators in designing and facilitating their own professional development in supportive communities. For example, might Faculty Learning Communities (FLCs) that usually have regular face-to-face meetings incorporate more participant-centric practices, or allow for untethered approaches to learning that allow in-person and online synchronous and asynchronous learning experiences? Could they support learner-chosen collaborative annotations and engagement in both private and public spaces? And how will their educators (and indeed education developers) be 
supported into their foray into the participatory and connected open web? FLCs are often timed to last a semester or year (Cox, 2004), but why would we not strive to build sustainable and sustained communities, with members leaving and rejoining but being able to remain in the same space for longer? How can they benefit from existing open opportunities such as Virtually Connecting, Marginal Syllabus and DigPINS? We encourage readers to explore these options in their own context.

\section{Abbreviations}

CMOOC: Connectivist Massive Open Online Course; FLC: Faculty Learning Community; MOOC: Massive Open Online Course; PLN: Personal Learning Network; VC: Virtually Connecting; xMOOC: eXtended Massive Open Online Course

\section{Acknowledgements}

Our ideas here build on the ideas and contributions of others in our PLN. We have referenced them where possible, but we know that even our original thought is a result of the buildup of knowledge we have constructed in conversation with many others.

\section{Funding}

No funding was involved in the preparation of this article.

\section{Availability of data and materials}

Not applicable. No data collection was conducted while preparing this article.

\section{Authors' contributions}

MB wrote the abstract, the history of faculty development, philosophical underpinnings, the collaborative annotation, dual pathway MOOCs, untethered faculty development and the discussion and conclusion, and co-wrote the Virtually Connecting section and semi-fictional narrative. AC wrote the reasoning behind our approach, the DigPINS section, and co-wrote the Virtually Connecting section and semi-fictional narrative and reviewed other parts of the article. Both authors read and approved the final manuscript.

\section{Authors' information}

N/A.

\section{Competing interests}

The authors are involved in some of the models mentioned:

- Maha Bali: co-founder and co-director of Virtually Connecting

- Autumm Caines: co-director of Virtually Connecting and facilitator of DigPINS, 2018.

- Both authors have participated in dual pathway MOOCs, TJC15 and Marginal Syllabus, and as such have relationships with the academics we cite who have worked on them, as well as the initiators of untethered faculty development approaches.

- Note that although we have removed all references to author names in the article, a reader who knows us personally is likely to figure out who we are from the context.

\section{Publisher's Note}

Springer Nature remains neutral with regard to jurisdictional claims in published maps and institutional affiliations.

\section{Author details}

${ }^{1}$ American University in Cairo, Virtually Connecting, Cairo, Egypt. ${ }^{2}$ St. Norbert College, Virtually Connecting, De Pere, USA.

Received: 19 July 2018 Accepted: 13 November 2018

Published online: 20 December 2018

\section{References}

Bali, M. (2018). Challenging Academic Gatekeeping: Open Scholarship and Virtually Connecting. In E/merge Africa Festival of eLearning [keynote address; online conference organized by University of Cape Town, South Africa].

Bali, M., Beckingham, S., Zamora, M., Caines, A., Hogue, R. J., \& Weller, M. (2017). Breaking the physical presence barrier: Virtually Connecting as an approach to open, inclusive conferences. Open Educational Resources (\#OER17). London, UK.

Bali, M., Caines, A., DeWaard, H., \& Hogue, R. (2016). Ethos and practice of a connected learning movement: interpreting virtually connecting through alignment with theory and survey results. Online Learning, 20(4) https://doi.org/10.24059/olj. v20i4.965.

Bali, M., Crawford, M., Jessen, R., Signorelli, P., \& Zamora, M. (2015). What makes a cMOOC community endure? Multiple participant perspectives from diverse cMOOCs. Educational Media International, 52(2), 100-115.

Bali, M., \& Hogue, R. J. (2015). Virtual, hybrid of present? The \#et4buddy conference experiment. Hybrid Pedagogy Retrieved from: http://hybridpedagogy.org/virtual-hybrid-or-present/. 
Bali, M., \& Sharma, S. (2014). Bonds of difference: participation as inclusion. Hybrid Pedagogy Retrieved from: http://www. hybridpedagogy.com/journal/bonds-difference-participation-inclusion/.

Beach, A., Sorcinelli, M. D., Austin, A. E., \& Rivard, J. K. (2016). Introduction. In A. Beach, M. D. Sorcinelli, A. E. Austin, \& J. K. Rivard (Eds.), Faculty development in the age of evidence: Current Practices, Future Imperatives, (pp. 1-15). Sterling: Stylus.

Beckingham, S. (2018). Using Social Media to Learn from Conferences. In C. Popovic (Ed.), Learning from Academic Conferences. Leiden: Brill | Sense.

Berman, A. M. (2015). Virtualizing the right part of the conference. In Virtually connecting [web log post] Retrieved from: http:// virtuallyconnecting.org/blog/2015/08/05/virtualizing-the-right-part-of-the-conference/.

Blaschke, L. (2012). Heutagogy and lifelong learning: a review of heutagogical practice and self-determined learning. International Review of Research on Open and Distributed Learning, 13(1), 56-71. Retrieved from: http://www.irrodl.org/ index.php/irrodl/article/view/1076/2087.

Cox, M. D. (2004). Introduction to faculty learning communities. New Directions for Teaching and Learning, 97, 5-23.

Cronin, C. (2014). Networked learning and identity development in open online spaces. In Proceedings of the 9th International Conference on Networked Learning Retrieved from http://www.lancaster.ac.uk/fss/organisations/netlc/past/nlc2014/ abstracts/pdf/cronin.pdf.

Crosslin, M. (2018). Exploring self-regulated learning choices in a customisable learning pathway MOOC. Australasian Journal of Educational Technology, 34(1), 131-144.

Czerniewicz, L. (2015). Considering inequality as higher education goes online [keynote address]. Association for Learning Technology Conference, Manchester, UK, September 9-10, 2015. Retrieved from: https:/www.youtube.com/watch?v=WEglB5b_msk.

DigPINS Course Structure (2018). Retrieved from https://digpins.org/course-structure/.

Downes, S. (2015). Becoming MOOC. [web log post]. Retrieved from: https://www.downes.ca/cgi-bin/page.cgi?post=64655.

Downes (2014). https://halfanhour.blogspot.com/2014/04/connectivism-as-learning-theory.html?m=1

Freire, P. (1970). Pedagogy of the oppressed (MB Ramos, Trans.). New York: Continuum.

Friederich, C. (2016). On Vconnecting at \#OEB16. In Virtually Connecting [web log post] Retrieved from: http:// virtuallyconnecting.org/blog/2016/12/09/friedelitis-on-vconnecting-at-oeb16/.

Full Spectrum Learning Stipend. (2018). Retrieved from https:/fullspectrumlearning.knight.domains/the-full-spectrumlearning-fsl-stipend/

Gee, J., \& Hayes, E. (2012). Nurturing affinity spaces and game-based learning. In C. Steinkuehler, K. Squire, \& S. Barab (Eds.), Games, Learning, and Society: Learning and Meaning in the Digital Age, (pp. 129-155). Cambridge: Cambridge University Press Accessed pre-print version at: http://jamespaulgee.com/pdfs/Affinity\%20Spaces.pdf.

Gogia, L. \& Warren, S (2015). A Careful Approach to Digital Scholarship. Hybrid Pedagogy. Retrieved from: http:// hybridpedagogy.org/careful-approach-to-digitalscholarship/.

Gorski, P. C., \& Pothini, S. G. (2013). Case studies on diversity and social justice education. New York: Routledge.

Hammershaimb, L. (2016). On blank spaces, being human, and the amazingness of virtually connecting. In Virtually Connecting [web log post] Retrieved from: http://virtuallyconnecting.org/blog/2016/06/26/on-blank-spaces-being-humanand-the-amazingness-of-virtually-connecting/.

Ito, M., Gutiérrez, K., Livingstone, S., Penuel, B., Rhodes, J., Salen, K. ... Watkins, C. (2013). Connected learning: An agenda for research and design. Irvine: Digital Media and Learning Research Hub. Retrieved from http://eprints.lse.ac.uk/48114/.

Jackson, S. (2018). Developing transformative spaces in higher education. Routledge. Oxon, New York: VitalBook file.

Kalir, J., \& Perez, F. (2019). The marginal syllabus: Educator learning and web annotation across sociopolitical texts and contexts. In A. Reid (Ed.), Marginalia in modern learning contexts. Hershey: IGI Global.

Kalir, J. H. (in press). Equity-oriented Design in Open Education. International Journal of Information and Learning Technology.

Koseoglu, S. (2015). Thought on Open Scholarship. In Virtually connecting [web log post] Retrieved from: http:// virtuallyconnecting.org/blog/2015/06/05/thoughts-on-open-scholarship/.

Leafstedt, J., \& Pacansky-Brock, M. (2016a). A step-by-step guide to untethered faculty development. Edsurge. Available at: https://www.edsurge.com/news/2016-10-06-a-step-by-step-guide-to-untethered-faculty-development

Leafstedt, J., \& Pacansky-Brock, M. (2016b). Faculty development in the age of digital connected learning. Edsurge. Available at: https:/www.edsurge.com/news/2016-12-15-faculty-development-in-the-age-of-digital-connected-learning

Mezirow (2006/2018). Transformative Learning. In K. Illeris (Ed.), Contemporary theories of learning, (2nd ed., ). London: Routledge. VitalBook file.

Morris, S. M., Rorabough, P., \& Stommel, J. (2013). Beyond rigor. Hybrid Pedagogy Retrieved from: http://www.hybridpedagogy com/journal/beyond-rigor/.

Palmer, P. J. (1998). The Courage to Teach: Exploring the Inner Landscape of a Teacher's Life. San Francisco: Jossey-Bass.

Ross, J., Sinclair, C., Knox, J., Bayne, S., \& Macleod, H. (2014). Teacher experiences and academic identity: the missing components of MOOC pedagogy. MERLOT Journal of Online Learning and Teaching, 10(1), 56-68 Retrieved from http:// jolt.merlot.org/vol10no1/ross_0314.pdf.

Siemens, G. (2004). Connectivism: A learning theory for the digital age. International Journal of Instructional Technology and Distance Education, 2(1). Retrieved December 3, 2018, from: http://www.itdl.org/journal/jan_05/article01.htm

Siemens, G. (2013). Massive open online courses: innovation in education. In R. McGreal (Ed.), Open Educational Resources: Innovation, Research and Practice, (1st ed.). Athabasca: UNESCO. Retrieved from: https://oerknowledgecloud.org/sites/ oerknowledgecloud.org/files/pub_PS_OER-IRP_CH1.pdf.

Siemens, G., \& Cormier, D. (2010). Through the open door: open courses as research, learning, and engagement. Educause Review Retrieved from: https://er.educause.edu/articles/2010/8/through-the-open-door-open-courses-as-research-learningand-engagement.

Watters, A. (2016). The Best Way to Predict the Future is to Issue a Press Release. Retrieved July 4, 2018, from http:// hackeducation.com/2016/11/02/futures

Wenger, E., Trayner, B., and de Laat, M. (2011) Promoting and assessing value creation in communities and networks: a conceptual framework. Rapport 18, Ruud de Moor Centrum, Open University of the Netherlands.

Zamora, M., \& Bali, M. (in press). Network. Digital Pedagogy in the Humanities: Concepts, Models and Experiments, Modern Language Association (MLA). First draft, with open peer review comments, available here: https://digitalpedagogy.mla. hcommons.org/keywords/network/ 